\title{
Dilated cardiomyopathy and the dystrophin gene: an illustrated review
}

\author{
Anders Oldfors, Bengt O Eriksson, Mårten Kyllerman, Tommy Martinsson, \\ Jan Wahlström
}

\begin{abstract}
Cardiomyopathy is often found in patients with Duchenne and Becker muscular dystrophy, which are $X$ linked muscle diseases caused by mutations in the dystrophin gene. Dystrophin defects present in many different ways and cases of mild Becker muscular dystrophy have been described in which cardiomyopathy was severe. Female carriers of Duchenne muscular dystrophy can develop symptomatic skeletal myopathy alone or combined with dilated cardiomyopathy. They can also develop dilated cardiomyopathy alone. $X$ linked dilated cardiomyopathy has been found in association with dystrophin defects. The relation between the molecular defects and the cardiac phenotypes has not yet been established. New mutations in the dystrophin gene are common and such mutations cause one third of the cases with Duchenne and Becker muscular dystrophy. This means that sporadic cases of cardiomyopathy caused by dystrophin defects are likely. This paper reports such a case in a boy of 14 who died of dilated cardiomyopathy. Before the cardiac investigation, which was performed one month before he died, he had not complained of muscular weakness. He had minor signs of limb girdle myopathy and slightly increased concentrations of serum creatine kinase. He was found to have an unusual deletion in the dystrophin gene.
\end{abstract}

Department of

Pathology,

Gothenburg

University, Sahlgren

Hospital, Gothenburg,

Sweden

A Oldfors

Department of

Paediatrics,

Gothenburg

University, East

Hospital, Gothenburg,

Sweden

B O Eriksson

M Kyllerman

Department of

Clinical Genetics,

East Hospital,

Gothenburg, Sweden

T Martinsson

J Wahlström

Correspondence to:

Dr Anders Oldfors,

Department of Pathology

Department of Pathology,

45 Göteborg, Sweden.

Accepted for publication 26 April 1994

\section{Duchenne and Becker muscular dystrophy}

Duchenne muscular dystrophy is a $\mathrm{X}$ linked disease with onset in early childhood that causes severe muscle wasting and death before 25 years of age. The gene involved in Duchenne muscular dystrophy was identified in 1987 and the corresponding protein was named dystrophin. ${ }^{12}$ The gene is very large and includes more than 70 protein encoding regions (exons). Dystrophin in skeletal and cardiac muscle is a $427 \mathrm{kD}$ protein with various functions. One major function that has been proposed is anchoring of the cytoskeletal protein actin to the dystrophin-associated glycoprotein complex in the plasma membrane of muscle cells. ${ }^{3}$ In Duchenne muscular dys-
(Br Heart F 1994;72:344-348) trophy there is pronounced deficiency of dys- trophin. This deficiency is usually caused by deletions or point mutations in the dystrophin gene which lead to a shift in the reading frame and produce a stop codon and deficient synthesis of dystrophin. ${ }^{4}$ Becker muscular dystrophy is a milder variant that is also caused by mutations in the dystrophin gene, usually deletions without shift in the reading frame. Patients usually can walk and have a normal life span. In some cases there are duplications of one or several exons. In Becker muscular dystrophy the amount of dystrophin is normal or near normal, but the protein is often smaller than normal and a segment corresponding to the deletion in the gene is missing. ${ }^{5}$ New techniques for investigating the dystrophin gene and gene product have shown that dystrophinopathy may be expressed clinically in many different waysfor example, as muscle cramps as the only symptom or high serum creatine kinase (s$\mathrm{CK})$ as the only evidence of muscle disease..$^{6-9}$ Female carriers of the mutation usually are symptom free, but some have symptoms. In some cases this may be due to a non-random inactivation of the $\mathrm{X}$ chromosomes, leading to a predominant expression of the $\mathrm{X}$ chromosome that has a mutation in the dystrophin gene. ${ }^{10}$

\section{Cardiomyopathy in Duchenne and \\ Becker muscular dystrophy}

Although muscle weakness is the presenting and predominant symptom in Duchenne muscular dystrophy, dilated cardiomyopathy is often seen and can be severe. ${ }^{11}$ Several cases of dilated cardiomyopathy have been described in patients with Becker muscular dystrophy ${ }^{9}{ }^{12-16}$ and some patients have had cardiac transplantation. ${ }^{17} 18$ Dilated cardiomyopathy, which is rarely the presenting symptom in Becker muscular dystrophy, usually appears in adulthood. However, Yoshida et al recently described four patients with Becker muscular dystrophy and deletions in the dystrophin gene who presented with cardiomyopathy. ${ }^{19}$ Two of these had no or slight muscle weakness and fatal myocardial involvement had developed when they were teenagers. Both had a deletion in exon 1 in the dystrophin gene.

In theory female carriers of Duchenne and Becker muscular dystrophy can show dystrophin defects in $50 \%$ of the mononucleated myocardial cells because of random inactivation of either the normal or mutated $\mathrm{X}$ chromosome. This fact can be used to identify 
female carriers by endomyocardial biopsy and immunostaining of the myocardium with antidystrophin antibodies. ${ }^{20}$ Female carriers of Duchenne and Becker muscular dystrophy often show clinical expression of myocardial involvement, ${ }^{21}{ }^{22}$ and cardiomyopathy can be the only clinical manifestation. ${ }^{23}$

\section{$\mathrm{X}$ linked dilated cardiomyopathy}

$\mathrm{X}$ linked cardiomyopathy is a rapidly progressive myocardial disorder presenting in teenage boys as a congestive heart failure without clinical signs of skeletal myopathy. ${ }^{24}$ Recently, X linked dilated cardiomyopathy in two pedigrees was shown to be linked to the Duchenne muscular dystrophy gene region $(\mathrm{Xp} 21)$ and associated with a cardiac dystrophin defect in the amino-terminal region, but the mutation was not identified..$^{25}$ There was an increase in muscle s-CK indicating skeletal muscle involvement. Muntoni et al described a deletion in the dystrophin muscle promoter region and exon 1 in one pedigree with $X$ linked dilated cardiomyopathy. ${ }^{26}$ All affected boys showed an increase in muscle s-CK, and muscle biopsy, which was performed in one case, showed mild myopathic changes. The reason why some patients with dystrophinopathy present with severe cardiomyopathy despite mild skeletal myopathy is not clear. This may partly be because dystrophin has different functions in skeletal and cardiac muscle. ${ }^{19}$ The presence of an additional C-terminal transcript of dystrophin in cardiac muscle that is not present in skeletal muscle further complicates the picture. ${ }^{3}$ Further studies including clinical and molecular investigations of cardiac tissue from patients with cardiomyopathy caused by defective dystrophin are needed to establish the relation between the genotype and the cardiac phenotype. ${ }^{27} 28$

A third of cases of Duchenne and Becker muscular dystrophies arise from new mutations, and a similar proportion of cases of dystrophinopathy with other clinical manifestations may also be caused by new mutations.

Figure 1

(A) Endomyocardial biopsy specimen showing interstitial fibrosis.

(B) Skeletal muscle biopsy specimen showing minor myopathic changes with increased variability of fibre diameter and central nuclei in some muscle fibres. Haematoxylin and eosin.
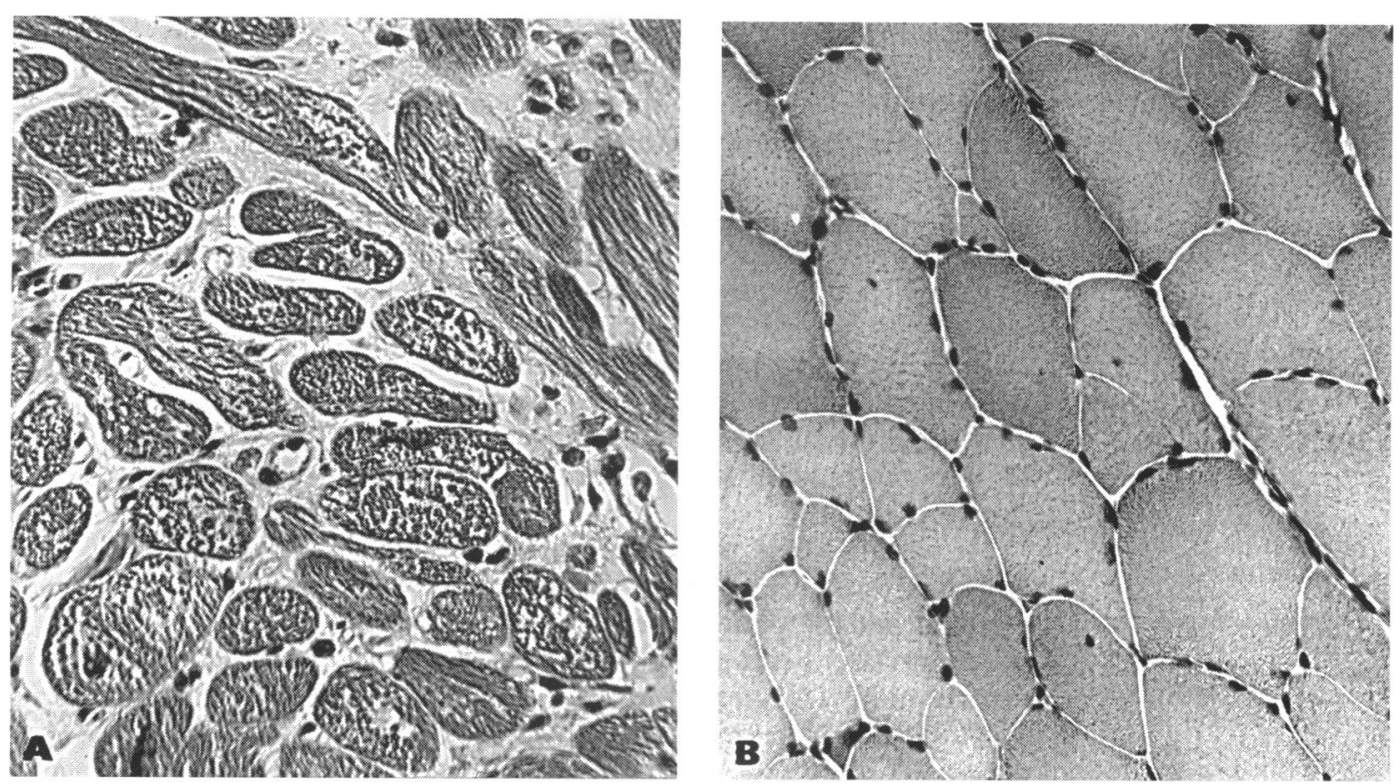

The possibility that sporadic cases of idiopathic dilated cardiomyopathy may be caused by dystrophin defects prompted a recent study on a large series of patients with dilated cardiomyopathy; no dystrophin gene defects were confirmed in any of these cases, ${ }^{29}$ however the muscle promoter region was not investigated and the patients were adults. As in X linked dilated cardiomyopathy, it may be that sporadic cases of cardiomyopathy as the only clinical manifestation of a dystrophin defect will be found mainly among young people especially if there is an increase in s-CK.

\section{Report of a case}

We describe a boy of 14 who died of dilated cardiomyopathy. Before the cardiac investigation, which was performed one month before he died, he had not complained of muscular weakness. He was found to have an unusual deletion in the dystrophin gene.

This boy was the second child of unrelated healthy parents. A younger sister had died in infancy of volvolus of the small intestine. An older brother, now 25 years of age, has no signs of cardiac or skeletal muscle disease and normal s-CK. Their mother has no signs of muscle disease and her s-CK is normal. There is no family history of cardiac or skeletal muscle disease.

The patient was referred for cardiac investigation in 1987 because of congestive heart failure with a two month history of weight loss, increasing fatigue, and periods of abdominal pain and vomiting after upper respiratory tract infections. On admission he showed signs of heart dysfunction with gallop rhythm, left ventricular hypertrophy, low blood pressure $(80 / 60 \mathrm{~mm} \mathrm{Hg}$ ), and severe heart enlargement on $x$ ray. Electrocardiography showed tachycardia, left atrial and ventricular hypertrophy, and strain. Echocardiography showed considerable dilatation of the left ventricle (diastolic diameter $82 \mathrm{~mm}$ ) and a fractional shortening of 


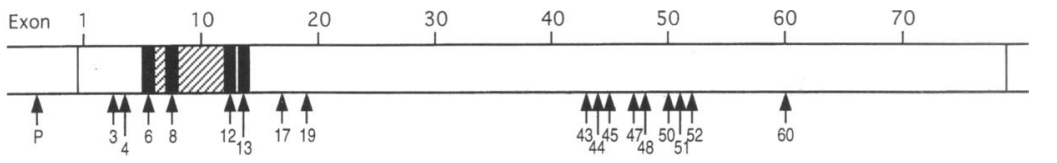

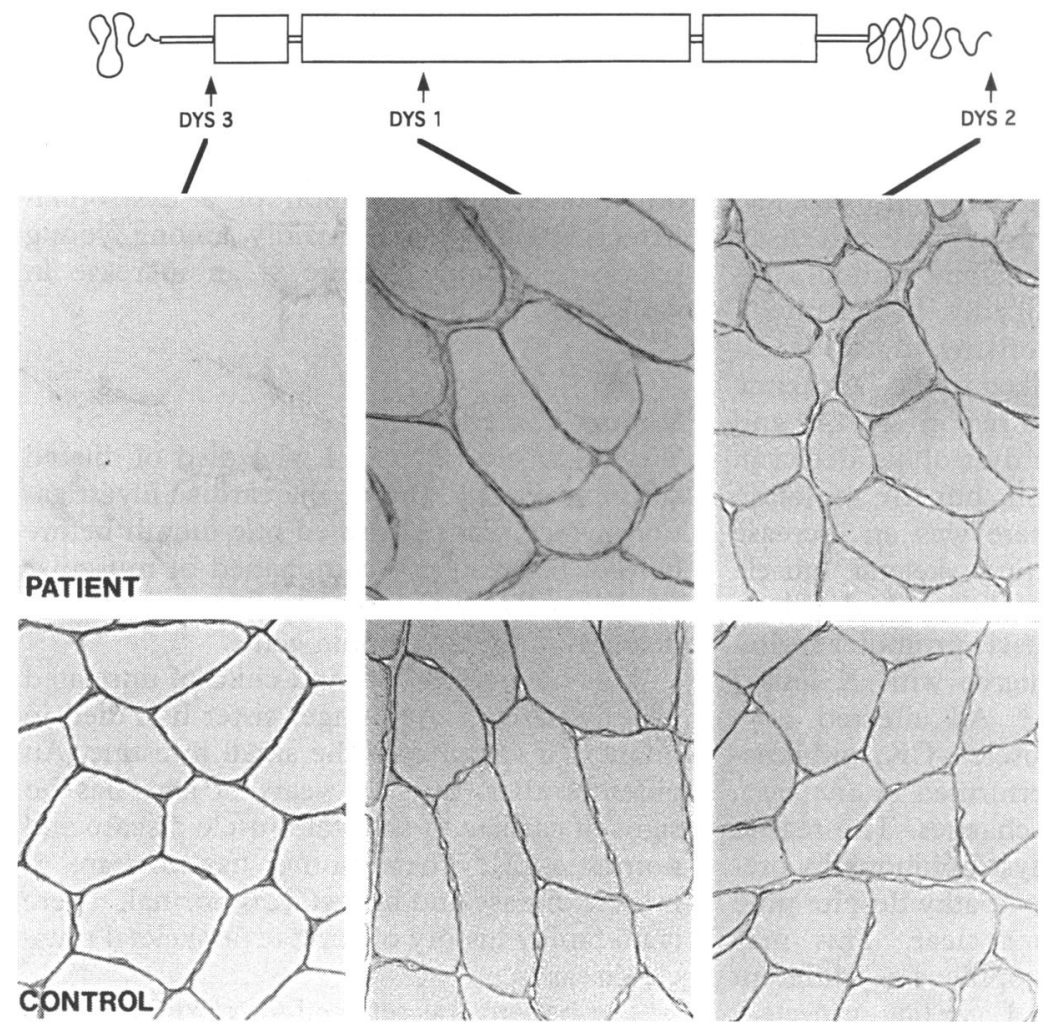

Figure 2 Results of the PCR and immunohistochemical investigation showing that the deletion in the dystrophin gene corresponds to the region of the epitope of the DYS 3 antibody, which show's no immunoreactivity in the patient. The upper part of the figure shows the dystrophin gene. The exons investigated by PCR reaction are indicated by arrows. $P$, muscle promoter. The deleted exons are indicated by solid bars. The hatched bars correspond to the exons, that are most likely to be deleted. The middle part of the figure shows the dystrophin molecule and the epitopes of the three monoclonal antibodies. ${ }^{8}$ The photographs illustrate the immunohistochemical staining of dystrophin in the patient (upper row) and a control (lower row) with the three antibodies.

$11 \%$. There was also considerable left atrial dilatation with a left atrial to aortic diameter ratio of 1.78 and a left atrial diameter of 41 $\mathrm{mm}$. The mixed venous oxygen saturation was only $42-52 \%$ indicating a very low cardiac output. Selective angiography excluded coronary artery abnormalities. An endomyocardial biopsy specimen was taken from the right ventricle and showed non-specific changes with interstitial fibrosis compatible with dilated cardiomyopathy (fig 1A).

Further clinical investigation showed mild generalised muscle weakness and slight muscular atrophy with a limb girdle distribution. In several samples, the concentration of s-CK was slightly raised $(5-15 \mu \mathrm{kat} / \mathrm{l}$ (normal $<3 \cdot 3$ $\mu \mathrm{kat} / \mathrm{l})$ ). Electromyography of the tibialis anterior, rectus femoris, and biceps brachii muscles was normal, whereas a biopsy specimen of skeletal muscle showed mild myopathic changes (fig 1B).

He was treated with digoxin, frusemide, and metoprolol. A cardiac transplantation was planned but the patient died one month later of congestive heart failure. A post-mortem examination was not performed.

The new knowledge of dystrophin prompted us to re-examine the muscle speci- men obtained in 1987. Immunohistochemical analysis of dystrophin was performed on cryostat sections with monoclonal anti-dystrophin antibodies (DYS 1, DYS 2, and DYS 3, Novocastra Laboratories, UK). The DYS 1 antibody recognises an epitope between amino acids 1181 and 1388 (exons 26 to 30 approximately), the DYS 2 antibody reacts with the last 17 amino acids of the carboxy terminal of dystrophin, and the DYS 3 antibody detects sequences between amino acids 308 and 351, spanning the junction of exons 9 and $10 .^{6}$ The immunoreactive material was visualised by the avidin-biotin complex (ABC)-peroxidase method with diaminobenzidine as chromogen. We performed Western blot analysis using the DYS 1 monoclonal antibody. ${ }^{3031}$ For molecular genetic analysis DNA was extracted from muscle tissue (the patient) or blood (the mother and brother). We used multiplex polymerase reaction (PCR) analysis to detect the presence or absence of 18 different deletion-prone regions of the dystrophin gene..$^{32}{ }^{33} \mathrm{We}$ used three different primer pairs to analyse dinucleotide repeats in the DMD gene region. ${ }^{34-36}$

Immunohistochemical staining showed normal or slightly reduced immunoreactivity with the antibodies DYS 1 and DYS 2 and no immunoreactivity with antibody DYS 3 (fig $2)$. The PCR reaction did not amplify exons $6,8,12$, and 13 . The other 14 investigated segments of the dystrophin gene were amplified in a normal way, indicating a deletion from exon 6 to exon 13 that did not involve exon 4 and exon 17 (fig 2). Western blot analysis with the antibody DYS 1 showed a dystrophin protein of reduced size (fig 3). These results show that a deletion in the dystrophin gene of the patient had shortened the dystrophin protein by removing a segment near the amino terminal region. The analysis of dinucleotide repeats showed that the patient and his healthy brother had received different haplotypes from their mother in the
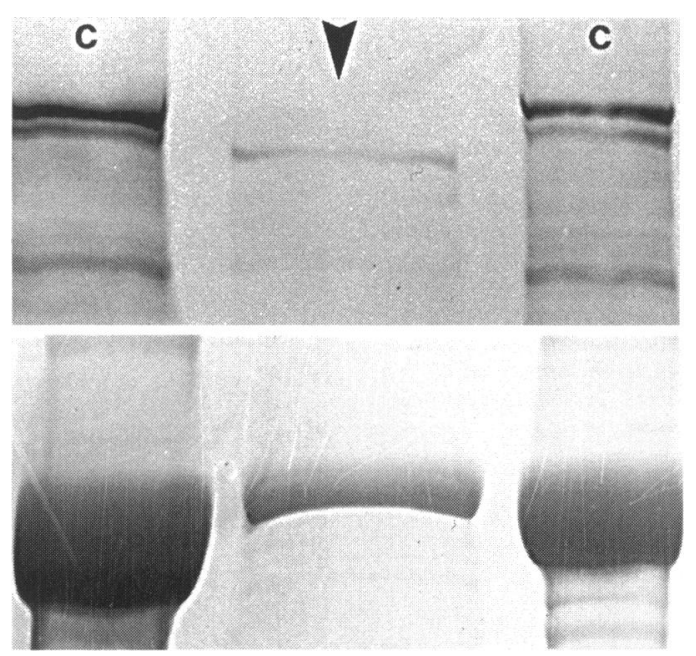

Figure 3 Result of Western blot analysis (upper lanes). The arrowed lane corresponds to the patient and shows the presence of dystrophin, which is smaller than in the controls (c). The intensity of the immunostaining is reduced because of the small amount of tissue available for analysis and is proportional to the reduced staining of the myosin band after staining with Coomassie blue (lower lanes). 
dystrophin gene. Therefore we could not unequivocally determine whether she is a carrier of the mutation.

\section{Comments}

Our patient had slight skeletal muscle involvement as judged by the small increase in s-CK and the minor muscle weakness; however, cardiac failure caused by dilated cardiomyopathy was severe. In this respect our case shows many features in common with patients in the recently described pedigrees with $\mathrm{X}$ linked dilated cardiomyopathy associated with dystrophin defects ${ }^{2526}$ caused by different mutations. Theoretically the deletion in our patient did not cause a shift in the reading frame; this accords with the presence of a truncated protein on the Western blot. Exons 9 and 10 are only rarely involved in deletions without a frame shift. ${ }^{63738}$ This part of dystrophin may be a hinge region joining the amino terminal domain to the central rod domain, and may thus be of great importance to the conformation of dystrophin. ${ }^{39}$ This region may be more important in cardiac muscle than in skeletal muscle because our patient had severe cardiac disease and mild skeletal myopathy. Or perhaps the amount of dystrophin was more severely reduced in the myocardium than in skeletal muscle. We did not have the opportunity to investigate dystrophin in the myocardium. The amount of dystrophin is important to the clinical expression. Beggs et al described a 7 year old boy with skeletal myopathy and an in frame deletion of exons 6-13, but unlike our case this patient had very little dystrophin in skeletal muscle. ${ }^{9}$

Though we could not unequivocally determine whether the mother of our patient is a carrier of the mutation, this case emphasises the importance of investigating the gene and gene expression of dystrophin not only in cases of muscular dystrophy and $\mathrm{X}$ linked dilated cardiomyopathy but also in sporadic cases of dilated cardiomyopathy, especially in young individuals with raised s-CK, because the results may have important implications for genetic counselling.

The study was supported by grants from the Swedish Medical Research Council (Proj no 7122, and 3921). We thank Dr Björn Westrup, Falun, Sweden, for his cooperation.

1 Hoffman M, Brown RH, Kunkel LM. Dystrophin: the protein product of the Duchenne muscular dystrophy protein product of the Duche
locus. Cell 1987;51:919-28.

2 Koenig M, Hoffman E, Bertelson C, Monaco A, Feener C, Kunkel L. Complete cloning of the Duchenne muscular dystrophy (DMD) cDNA and preliminary genomic organization of the DMD gene in normal and affected individuals. Cell 1987;50:509-17.

3 Ahn AH, Kunkel LM. The structural and functional diversity of dystrophin. Nature Genetics 1993;3:283-91.

4 Hoffman E, Kunkel L. Dystrophin abnormalities in Duchenne/Becker muscular dystrophy. Neuron 1989; 2:1019-29.

5 Koenig M, Beggs AH, Moyer M, Scherpf S, Heindrich K, Bettecken T, et al. The molecular basis for Duchenne versus Becker muscular dystrophy: correlation of severity with type

6 Nicholson LVB, Johnson MA, Bushby KMD, GardnerMedwin D, Curtis A, Ginjaar IB, et al. Integrated study of 100 patients with Xp21 linked muscular dystrophy using
clinical, genetic, immunochemical, and histopathologi- cal data. Part 1. Trends across the clinical groups. $f \mathrm{Med}$ Genet 1993;30:728-36.

7 Nicholson LVB, Johnson MA, Bushby KMD, GardnerMedwin D, Curtis A, Ginjaar IB, et al. Integrated study of Medwin D, Curtis A, Ginjaar IB, et al. Integrated study of
100 patients with Xp21 linked muscular dystrophy using clinical, genetic, immunochemical, and histopathological data. Part 3. Differential diagnosis and prognosis. f Med Genet 1993;30:745-51.

8 Nicholson LVB, Johnson MA, Bushby KMD, GardnerMedwin D, Curtis A, Ginjaar IB, et al. Integrated study of 100 patients with Xp21 linked muscular dystrophy using clinical, genetic, immunochemical, and histopathological data. Part 2. Correlations within individual patients. f Med Genet 1993;30:737-44.

9 Beggs AH, Hoffman EP, Snyder JR, Arahata K, Specht L, Shapiro F, et al. Exploring the molecular basis for variability among patients with Becker muscular dystrophy-dystrophin gene and protein studies. Am $\mathcal{F}$ Hum Genet 1991;49:54-67.

10 Hoffman EP, Arahata K, Minetti C, Bonilla E, Rowland LP, Angelini C, et al. Dystrophinopathy in isolated cases of myopathy in females. Neurology 1992;42:967-75.

11 Nigro G, Comi L, Politano L, Bain R. The incidence and evolution of cardiomyopathy in Duchenne muscular dystrophy. Int $\mathcal{f}$ Cardiol 1990;26:271-7.

12 Katiyar BC, Misra S, Somani PN, Chatejri AM Congestive cardiomyopathy in a family of Becker's X linked muscular dystrophy. Postgrad Med $\mathcal{f}$ 1977;53: $12-5$.

13 Palmucci L, Doriguzzi C, Mongini T, Chiadopiat L, Restagno G, Carbonara A, Paolillo V. Dilating cardiomyopathy as the expression of Xp21 Becker type muscular dystrophy. $\mathcal{F}$ Neurol Sci 1992;111:218-21.

14 Steare SE, Dubowitz V, Benatar A. Subclinical cardiomyopathy in Becker muscular dystrophy: Br Heart $f 1992$; 68:304-8.

15 Lazzeroni E, Favaro L, Botti G. Dilated cardiomyopathy with regional myocardial hypoperfusion in Becker's muscular dystrophy. Int $\mathcal{f}$ Cardiol 1989;22:126-9.

16 Melacini P, Fanin M, Danieli GA, Fasoli G, Villanova C, Angelini C, et al. Cardiac involvement in Becker muscular dystrophy. $\mathcal{F}$ Am Coll Cardiol 1993;22:1927-34.

17 Donofrio PD, Challa VR, Hackshaw BT, Mills SA Cordell AR. Cardiac transplantation in a patient with Cordell AR. Cardiac transplantation in a patient with
muscular dystrophy and cardiomyopathy. Arch Neurol muscular dystroph

18 Casazza F, Brambilla G, Salvato A, Morandi L, Grande E, Bonacina E. Cardiac transplantation in Becker muscular dystrophy. $f$ Neurol 1988;253:496-8.

19 Yoshida K, Ikeda S, Nakamura A, Kagoshima M, Takeda S, Shoij S, Yanagisawa N. Molecular analysis of the Duchenne muscular dystrophy gene in patients with Becker muscular dystrophy presenting with dilated cardiomyopathy. Muscle Nerve 1993;16:1161-6.

20 Schmidt-Achert M, Fischer P, Mullerfelber W, Mudra H, Pongratz D. Heterozygotic gene expression in endomyocardial biopsies-a new diagnostic tool confirms the Duchenne carrier status. Clin Investigator 1993;71: 247-53.

21 Comi LI, Nigro G, Politano L, Petretta VR. The cardiomyopathy of Duchenne/Becker consultants. Int $\mathcal{f}$ Cardiol 1992;34:297-305.

22 Kamakura $K$, Kawai $M$, Arahata $K$, Koizumi $H$, Watanabe $\mathrm{K}$, Sugita $\mathrm{H}$. A manifesting carrier of Duchenne muscular dystrophy with severe myocardial Duchenne muscular dystrophy with
symptoms. $₹$ Neurol 1990;237:483-5.

23 Mirabella M, Servidei S, Manfredi G, Ricci E, Frustaci A Bertini E, et al. Cardiomyopathy may be the only clinical Bertini E, et al. Cardiomyopathy may be the only clinical manifestation in female carriers of Duch
dystrophy. Neurology 1993;43:2342-5.

24 Berko BA, Swift M. X linked cardiomyopathy. N Engl $\mathcal{F}$ Med 1987;316:1186-91.

25 Towbin JA, Hejtmancik JF, Brink P, Gelb B, Zhu XM, Chamberlain JS, McCabe ERB, Swift M. X linked dilated cardiomyopathy - molecular genetic evidence of linkage to the Duchenne muscular dystrophy (dystrophin) gene at the Xp21 locus. Circulation 1993; 87:1854-65.

26 Muntoni F, Cau M, Ganau A, Congiu R, Arvedi G, Mateddu A, et al. Brief report-deletion of the dystrophin muscle-promoter region associated with X
linked dilated cardiomyopathy. $N$ Engl $\mathcal{F}$ Med 1993; 329:921-5.

27 Bies RD. X linked dilated cardiomyopathy. N Engl F Med 1994;330:368-9.

28 Towbin JA, Ortizlopez R. X linked dilated cardiomyopathy. N Engl f Med 1994;330:369-70.

29 Michels VV, Pastores GM, Moll PP, Driscoll DJ, Miller FA, Burnett JC, et al. Dystrophin analysis in idiopathic FA, Burnett JC, et al. Dystrophin analysis in idiopathic
dilated cardiomyopathy. $\Im$ Med Genet 1993;30:955-7.

30 Nicholson LVB, Davison K, Falkous G, Harwood C, O'Donell E, Slater CR, Harris JB. Dystrophin in skeletal O'Donell E, Slater CR, Harris JB. Dystrophin in skeletal muscle I. Western blot analysis using
body. $\mathcal{F}$ Neurol Sci 1989;94:125-36.

31 Nicholson LVB, Johnson MA, Gardner-Medwin D, Bhattacharya S, Harris JB. Heterogeneity of dystrophin expression in patients with Duchenne and Becker muscular dystrophy. Acta Neuropathol (Berl) 1990;80 239-50.

32 Beggs AH, Koenig M, Boyse FM, Kunkel LM. Detection of 98 percent of DMD/BMD gene deletions by polymerase chain reaction. Hum Genet 1990;86:45-8.

33 Chamberlain JS, Gibbs RA, Ranier JE, Caskey CT Multiplex PCR for the diagnosis of Duchenne muscula 
dystrophy. In: Innis MA, Gelfand DH, Sninsky J, White TJ, eds. PCR protocols: a guide to methods and applications. San Diego: Academic Press, 1990: application

34 Hugnot JP, Recan D, Jeanpierre M, Kaplan JC, Tolun A. A highly informative CACA repeat polymorphism upstream of the human dystrophin gene (DMD). Nucleic Acid Res 1991;19:3159.

35 Clemens PR, Fenwick RG, Chamberlein JS, Gibbs RA Deandrade M, Chakraborty R, Caskey CT. Carrie detection and prenatal diagnosis in Duchenne and Becker muscular dystrophy families, using dinucleotide repeat polymorphisms. Am f Hum Genet 1991;49: repeat

36 Powell JF, Foder FH, Cockburn DJ, Monaco AP, Craig
IW. A dinucleotide repeat polymorphism at the DMD locus. Nucleic Acid Res 1991;19:1159.

37 Chamberlain JS, Chamberlain JR, Fenwick RG, Ward PA, Caskey CT, Dimnik LS, et al. Diagnosis of Duchenne and Becker muscular dystrophies by polymerase chain reaction-A multicenter study. $\mathcal{A} A M A$ 1992;267: 2609-15.

38 Niemann-Seyde S, Slomski R, Rininsland F, Ellermeyer U, Kwiatkowska J, Reiss J. Molecular genetic analysis of 67 patients with Duchenne/Becker muscular dystrophy. Hum Genet 1992;90:65-70.

39 Koenig M, Kunkel LM. Detailed analysis of the repeat domain of dystrophin reveals four potential hinge segments that may confer flexibility. $\mathcal{F}$ Biol Chem 1990; 265:4560-6. 